\title{
Electrical Characterization of PV Modules employing Supercapacitors - A Scalable Method for Field Metrology
}

\author{
S. Basu Pal ${ }^{1}$, Prof. K. Das (Bhattacharya) ${ }^{1}$, Prof. D. Mukherjee ${ }^{2}$, D. Paul ${ }^{3}$ \\ ${ }^{1}$ Department of Electrical Engineering \\ Indian Institute of Engineering Science and Technology, Shibpur \\ P.O. Botanic Garden, Shibpur \\ Howrah, West Bengal 711103, India \\ Email:sudipta_basu68@yahoo.com,poopoolee50@hotmail.com \\ ${ }^{2}$ Department of Electronics and Telecommunication Engineering \\ Indian Institute of Engineering Science and Technology, Shibpur \\ P.O. Botanic Garden, Shibpur \\ Howrah, West Bengal 711103, India \\ Email:dipankarm@rediffmail.com \\ ${ }^{3} \mathrm{SSBB}, \mathrm{ASQ}$ \\ Kolkata, India \\ Email: debkalyan_paul@yahoo.co.in
}

\begin{abstract}
Photovoltaic (PV) Energy Conversion is currently the most trusted potential avenue for generating electrical power. Currently, the price of conventional grid electricity is globally on the rise, where as the prices of PV modules (building Blocks for any PV system) are gradually on the decline. So there is every reason to trust that Solar Photo-voltaic systems (SPS) will emerge as a cheap and decentralized source of electricity in a big way in course of a decade. In the measurement procedure followed by the authors, Supercapacitor(s) are used as load to the PV module under test. A detailed investigation regarding quality of measurements has been carried out taking into consideration the effect of a wide range of climatic variations. Experimental values of fill-factor and peak power over a broad range of insolation spectrum have been obtained which yield a fairly consistent pattern for varying capacities of PV modules. Regression analysis for linearity check has been done to establish the effectiveness and reliability of the developed characterization system.
\end{abstract}

\section{KEYWORDS}

PV Characterization, Field Testing, Supercapacitor, Measurement Quality, Scalability

\section{Introduction}

In the photovoltaic field, manufacturers provide ratings for PV modules for conditions referred to as standard test conditions (STC). However, these STC conditions rarely occur in outdoor. So, to carry out photovoltaic engineering accurately, a suitable method for quick \& reliable characterization of PV module electrical behavior (V-I curves) in actual field condition is essential [1]. Also, the process must be portable, scalable and cost effective for wide-spread adoption. Characterization of Photovoltaic(PV) generators have been practiced by different research groups for determining their essential electrical parameters[2]. Such practices conventionally use a variable load compatible with the wattage of a PV array. Methods for plotting the V-I characteristics of a PV cell/module were initiated with analog approaches. Obviously, such analog methods [3] are constrained by (a) Need to extrapolate the curve at the extremities of 'short circuit current' and 'open circuit 
voltage' points, leading to inaccuracies in estimates of the values of parasitic resistances (b) Thermal effect on the photovoltaic performances when the plotting time exceeds a certain limit. An improved electronic circuit for testing photovoltaic (PV) modules or strings by tracing their V-I and P-V characteristics was introduced by Vicente Leite and Faustino Chenlo[4]. Their circuit consists of an electronic fast varying load based on a power MOSFET controlled by means of an innovative sweeping gate-source voltage in order to improve the tracing of the V-I characteristics on an oscilloscope. A developed technique for presenting the solar cell characteristics using LAB-VIEW has been developed by Yousry Atia et al [5]. But these are often unsuitable for real time field operations on account of portability, compactness and cost of instrumentation. Of late, there is an effort by Marwan. M. Mahmoud et al [6], enabling the selection of a particular capacitance value as the load. Such practices are seen to be confronted by (a) difficulty is use of X-Y Recorders or Compatible Data Acquisition systems (DAS) and (b) lack of suitable model predicting to the plotting time. In this backdrop, the authors of this paper have developed a method of PV characterization using Supercapacitors as the load to the PV generators. It is observed that a common DAS performs suitably \& also the plotting time can be controlled accurately by choosing the right value of Supercapacitors. The authors have used tested the new method using supercapacitors as load for tracing V-I curve as load of PV modules of varying wattages [7]. Further the authors have thoroughly evaluated the quality of measurement in this novel metrological approach.

\section{USING SUPERCAPACITOR AS A LOAD}

The supremacy of this method is established from the smooth and ripple free V-I characterization. This yields accurate determination of module electrical parameters [7]. It is also a cost effective proposition compared to capacitive method as Supercapacitor calls for a moderate scanning speed, a reduced device complexity than the capacitive method in conjunction with a compatible Data Acquisition System (DAS).In the capacitive method described by M.Mahamoud [6], the author has given an expression of characterization time involving $\mathrm{C}, I_{s c}$ and $V_{o c}$ only. It is obviously insufficient as only open and short circuit points cannot define a whole I-V curve.

The author's have already developed a theoretical model for estimating V-I plotting time, taking into consideration the effect of Effective Series Resistance (ESR) value of the supercapacitor also. Recent results [8] communicated by Pal et al indicates very close agreement between the experimental plotting time with the theoretical estimated value. Typical values of curve plotting time are shown in table 2 for 10 Watt poly-Si module.

Table 2: Plotting Time chart for 10watt Poly-Si module using different Supercapacitor values

\begin{tabular}{|c|c|c|}
\hline $\begin{array}{c}\text { Insolation } \\
\left(\text { watt } / \mathrm{m}^{2}\right)\end{array}$ & $\begin{array}{c}\text { Sc-value } \\
\text { (farad) }\end{array}$ & $\begin{array}{c}\text { Plotting time } \\
(\mathrm{Sec})\end{array}$ \\
\hline 900 & 0.025 & 9 \\
\hline 900 & 0.02 & 8 \\
\hline 900 & 0.0166 & 7.4 \\
\hline 900 & 0.0125 & 7 \\
\hline 900 & 0.01 & 6.6 \\
\hline
\end{tabular}

\section{EXPERIMENTAL SETUP}

The block diagram of the complete testing scheme is shown in figure 3.1.

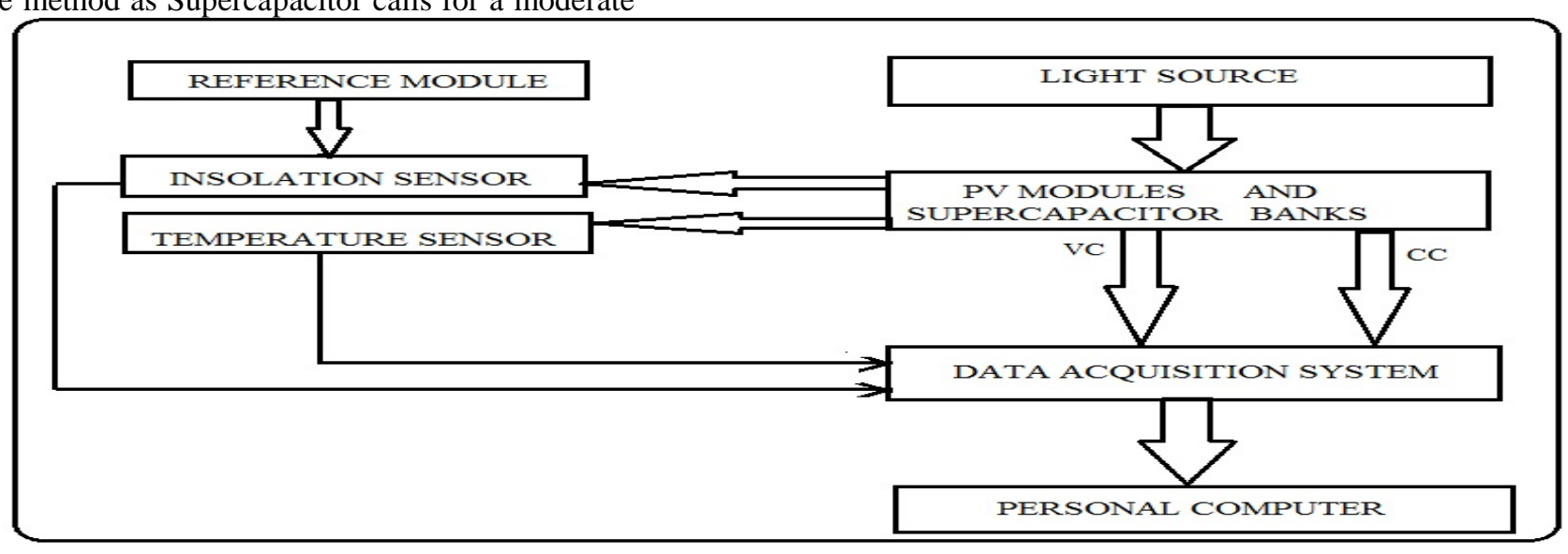

Figure 3.1: Block diagram of Experimental Setup where VC denotes voltage channel and CC denotes current channel 


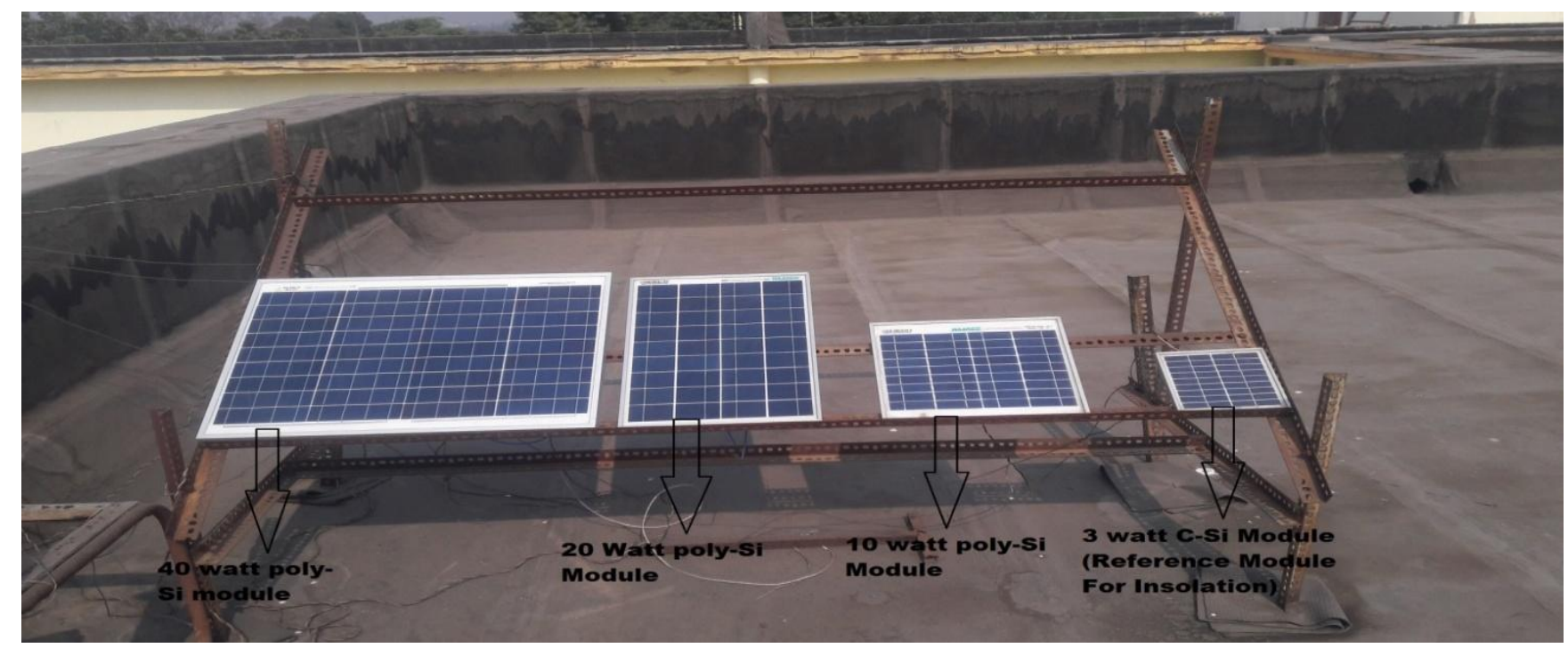

Figure 3.2: Rooftop test setup

Here the device under test (DUT) is a solar PV Module or Panel (Combination of PV Modules) lying on a RoofTop steel (Nut and Bolted) structure (Figure 3.2). Here, it can be seen that a standard 3 watt PV module of C-Si (at the right hand most corner) placed in the same horizontal plane has been used as the Reference module for insolation sensing. The temperature is measured using IR-thermometer (TESTO 830T1). The DAS used here is Agilent 34970A capable of scanning with millisecond interval. To control the DAS from computer, a Graphical User Interface named Agilent Bench Link Data Logger has been used. To constitute the appropriate Supercapacitor bank, 20 number of $5.5 \mathrm{~V} \quad 0.1 \mathrm{~F}$ Supercapacitors have been procured

\section{Experimental Results}

A wide set of experimental data have been procured for varying wattages of PV modules under varying climatic conditions (at different time of the day in different seasons) with appropriate supercapacitor values as the load. The V-I characterization of Crystalline Si module and Poly Si module using different test conditions and supercapacitor values have been recorded in the experimental setup. Few samples of the V-I curves are shown in figure 4.a to figure 4.d, pertaining to poly-Si PV modules only, of different wattages (Poly Si modules of assorted variety currently has the major local market share). 


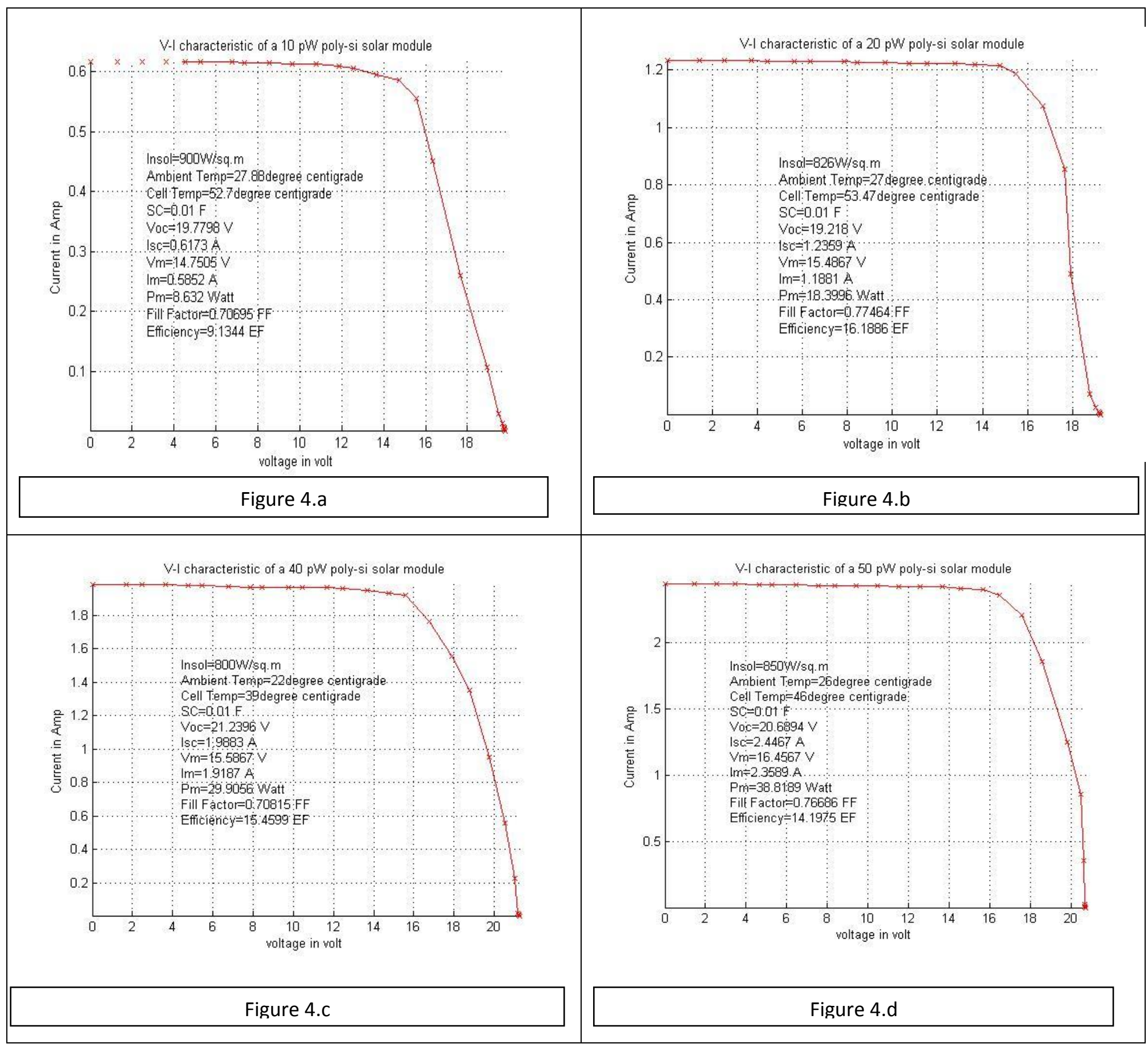

Figure 4: V-I characteristics of various Poly-Si modules (Choosing minimum plotting time)

\section{Quality Analysis of PV Measurement}

To ascertain the quality of PV metrology the following two checks were conducted by the authors

a) Regression Analysis of selected PV Parameters ( $I_{s c}, I_{m}$ and $\mathrm{P}_{\mathrm{m}}$ ) with reference to varying insolation have been compiled with the aid of ref [9]

b) Consistency of Fill Factor variation with Solar Insolation In terms of Standard deviation Calculation

\subsection{Regression Analysis:}

Table 5.1 below establishes that the regression coefficient value of the parameters generated by the supercapacitive method is constantly above 0.9 
Table 5.1.: Regression Analysis of PV parameters for 10 Watt Poly-Si Module

\begin{tabular}{|c|c|c|c|c|}
\hline $\begin{array}{l}\text { Type of PV } \\
\text { Module Under test }\end{array}$ & $\begin{array}{l}\text { Wattage of PV } \\
\text { Module Under } \\
\text { Test (Watt) }\end{array}$ & $\begin{array}{l}\text { Value of Supercapacitor Used for } \\
\text { characterization }\end{array}$ & PV characterization Parameters & $\begin{array}{l}\text { Linearity of PV } \\
\text { parameters Value or } \\
\text { Regression } \\
\text { Value }\left(\mathrm{R}^{2}\right) \\
\end{array}$ \\
\hline \multirow{21}{*}{ Poly-Si } & \multirow{21}{*}{10} & 0.025 & Isc & 0.948 \\
\hline & & 0.02 & Isc & 0.957 \\
\hline & & 0.0166 & Isc & 0.951 \\
\hline & & 0.0125 & Isc & 0.956 \\
\hline & & 0.01 & Isc & 0.957 \\
\hline & & 0.066 & Isc & 0.972 \\
\hline & & 0.1 & Isc & 0.966 \\
\hline & & 0.025 & $\mathrm{Im}$ & 0.977 \\
\hline & & 0.02 & $\mathrm{Im}$ & 0.999 \\
\hline & & 0.0166 & $\mathrm{Im}$ & 0.9 \\
\hline & & 0.0125 & $\mathrm{Im}$ & 0.998 \\
\hline & & 0.01 & $\mathrm{Im}$ & 0.982 \\
\hline & & 0.066 & $\mathrm{Im}$ & 0.974 \\
\hline & & 0.1 & $\mathrm{Im}$ & 0.9 \\
\hline & & 0.025 & $\mathrm{Pm}$ & 0.969 \\
\hline & & 0.02 & $\mathrm{Pm}$ & 0.998 \\
\hline & & 0.0166 & $\mathrm{Pm}$ & 0.9 \\
\hline & & 0.0125 & $\mathrm{Pm}$ & 0.998 \\
\hline & & 0.01 & $\mathrm{Pm}$ & 0.989 \\
\hline & & 0.066 & $\mathrm{Pm}$ & 0.97 \\
\hline & & 0.1 & $\mathrm{Pm}$ & 0.989 \\
\hline
\end{tabular}

\subsection{Consistency check of the Measurement through Fill}

\section{Factor}

Standard Deviation (SD) estimated using equation 5 have been carried out in table 5.2 below

$$
\sigma=\sqrt{\frac{\sum(X-\vartheta)^{2}}{N} \ldots}
$$

Where $X$ represents each value of Fill Factor, $\mu$ is the mean value of the Fill Factor samples, $\sum$ is the summation (or total), and $\mathrm{N}$ is the number of values in the sample.

Table 5.2: Standard Deviation of Fill-Factor using supercapacitive load method

\begin{tabular}{|c|c|c|c|}
\hline $\begin{array}{c}\text { Type of PV Module } \\
\text { Under Test }\end{array}$ & $\begin{array}{c}\text { Wattage of PV } \\
\text { module } \\
\text { Under test } \\
\text { (Peak Watt) }\end{array}$ & $\begin{array}{c}\text { Value of supercapacitor used for } \\
\text { characterizing } \\
\text { (Farad) }\end{array}$ & $\begin{array}{c}\text { Standard Deviation } \\
\text { (SD) }\end{array}$ \\
\hline Poly-Si & 10 & 0.1 & 0.010823 \\
\hline Poly-Si & 10 & 0.066 & 0.023186 \\
\hline Poly-Si & 10 & 0.025 & 0.008709 \\
\hline Poly-Si & 10 & 0.02 & 0.014651 \\
\hline Poly-Si & 10 & 0.0166 & 0.008637 \\
\hline Poly-Si & 10 & 0.0125 & 0.023417 \\
\hline Poly-Si & 10 & 0.01 & 0.010884 \\
\hline
\end{tabular}




\section{CONCLUSION}

Besides, the smoothness and visibly good shape of the characteristics, obtained experimental results clearly demonstrate the following:

I. Table 2.1 shows that use of $0.01 \mathrm{~F}$ supercapacitor value ensures an acceptable plotting time of 6 to 7 seconds.

II. As seen from figure 4.a to 4.d the value of Fill Factor irrespective of module size and climatological parameters is restricted within $70 \%$ to $78 \%$

III. Estimated value of $R_{\mathrm{s}}$ in table 5.1 varies from $7.5 \mathrm{ohm}$ to $11 \mathrm{ohm}$, which is almost in confirmity with the values of $R_{s}$ ascertained earlier by PASAN TESTER (version 2.1.2).[10]

IV. Estimate of module efficiency shows a consistent value for particular module wattage.

V. The value of Regression co-efficient for the parameters $\mathrm{I}_{\mathrm{sc}}, \mathrm{I}_{\mathrm{m}}, \mathrm{P}_{\mathrm{m}}$ is consistently high in the range of 0.9 to 0.99 .

VI. Also, the accuracy of measurements indicated in terms of standard deviation estimate of FillFactor in table 5.2 seems quite satisfactory.

\section{REFERENCES}

[1] F. Almonacid, C. Rus.Casas, L. Hontoria,G. Nofuentes, "Characterisation of Si-crystalline PV modules by artificial neural networks", Renewable Energy 34 ,pp- 941-949,2009.

[2] D. Mukherjee and S. Chakrabarti, Fundamentals of Renewable Energy Systems, 1st ed., New Delhi, India: New Age International (P) Ltd., June. 2004.

[3] F. Granck and T. Zdanwich, "Advanced System for characterization and Calibration of Solar Cells," OptoElectronics Review, vol. 12, no. 1, pp. 57-67, 2004

[4] Vicente Leite and Faustino Chenlo, "An Improved Electronic Circuit for Tracing the I-V Characteristics of Photovoltaic Modules and Strings", International Conference on Renewable Energies and Power Quality, Granada (Spain), 23th to 25th March,2010.

[5]Yousry Atia, and Mohamed Zahran ,Abdullah alHossain," "Solar Cell Curves Measurement Based on Lab VIEW Microcontroller Interfacing", Proceedings of the 12th WSEAS International Conference on AUTOMATIC CONTROL, MODELLING \& SIMULATION,2010

[6] M. M. Mahmoud, "Transient analysis of a PV power generator charging a capacitor for measurement of the IV characteristics," Renewable Energy, Vol. 31, pp. 2198-2206, 2006.
[7] S. Basu Pal, T. Belel, K. Das (Bhattacharya), D. Mukherjee, "A Simple cost Effective method of characterizing PV Cell/Modules using Supercapacitor", WCPEC6-November-2014,Kyoto,Japan.

[8] S. Basu Pal, K. Das (Bhattacharya), D. Mukherjee, D.Paul, "Estimating of Curve tracing Time in Supercapacitor based PV Characterization", Journal of the Institution Engineers (India) Series B, Springer Series. Accepted for publication, Manuscript No: IEIBD-15-00189R1

[9] Douglas C Montgomery, Elizabeth A Peck, G. Geoffrey Vining, Introduction to Linear Regression Analysis, Third Edition, Willey Publishers

[10] PASAN SOLAR SIMULATOR, "Electronics Regional Test Laboratory, East, India". 